\title{
ENTREVISTA COM MARTINE SEGALEN Qual é a Antropologia do parentesco e da família no século XX|? Um diálogo franco e brasileiro com Martine Segalen
}

\section{Ana Luiza Carvalho da Rocha}

\section{Cornelia Eckert}

Luiz Eduardo R. Achutti

Universidade Federal do Rio Grande do Sul - Brasil

\section{Sophie Chevalier}

\section{Université de Franche-Comté - França}

Martine Segalen é antropóloga, professora na Universidade de Paris XNanterre, França e diretora do seu Departamento de Sociologia. Foi diretora de pesquisa no CNRS, vinculada ao "Centre d'Ethnologie Française et Musée des Arts et Traditions Populaires", que dirigiu durante vários anos. Seus livros e artigos sobre parentesco e família têm sido presença constante nas disciplinas de Antropologia de graduação e pós-graduação em universidades brasileiras.

O tema da natureza e cultura, privilegiado neste número de Horizontes antropológicos, foi desenvolvido na Antropologia clássica a partir de estudos sobre as relações de parentesco, as relações políticas, simbólicas, religiosas, etc. Neste contexto, a obra de Claude Lévi-Strauss é referência de um processo de transformação no interior da disciplina pois, ao buscar a compreensão das estruturas das idéias em sociedades simples e suas diferenças em relação a nossa própria sociedade, este autor renovou a premissa comparativa da Antropologia, até aquele momento concentrada na diferença das sociedades por sua evolução técnica e material. 
Este contexto acadêmico favorável aos novos desafios que a disciplina colocava em meados do século XX, foi cenário de surgimento de uma geração de antropólogos com propostas inovadoras na escola de Antropologia francesa.

"Objetivamente, as sociedades contemporâneas e as dos povos ditos primitivos, não são da mesma ordem de grandeza", como disse Claude Lévi-Strauss, tratando sobretudo da escrita, que fixa o conhecimento e gera a transmissão de saberes acumulados, construtora de tempos e espaços de uma outra lógica de ser no mundo. Este autor se referia à civilização ocidental como uma ordem cultural marcada por uma distinção em relação às sociedades simples. A questão inspiradora de Lévi-Strauss em sua obra é a diferença profunda entre nossa sociedade e as sociedades ditas primitivas. Conhecemos os estudos que este mestre delineou sobre sociedades "frias" e "quentes". E é sobre estas ultimas, as sociedades ditas complexas, que queremos aqui tratar, alargando nosso panorama sobre a pesquisa antropológica voltada às sociedades do contrato social e do sujeito da razão. Sociedades urbano-industriais que, ao mesmo tempo que se destacam por professar os postulados do individualismo moderno, pela mobilidade dos grupos sociais e dispersão espacial dos grupos familiares, se afirmam na busca minuciosa e freqüentemente fantasmática de suas origens ancestrais. Qual seria, portanto, hoje, a pertinência da teoria clássica do parentesco para os estudos antropológicos no contexto do desenraizamento das relações sociais no mundo contemporâneo? Que sentido ainda existe para a família e as relações de parentesco em nossas sociedades que praticam a fecundação artificial e investem, cada vez mais, na produção de embriões humanos?

Martine Segalen é herdeira desta ambiência desafiadora dos estudos estruturalistas, que caracteriza suas pesquisas sobre parentesco e família voltadas, de forma inovadora, para as sociedades contemporâneas, ainda que sua trajetória profissional nos revele uma produção científica eclética e igualmente aberta ao diálogo interdisciplinar.

Nesta oportunidade trazemos a conversa com a antropóloga realizada em junho de 2001, em sua residência em Neuilly, França. 
Martine Segalen e seus entrevistadores.

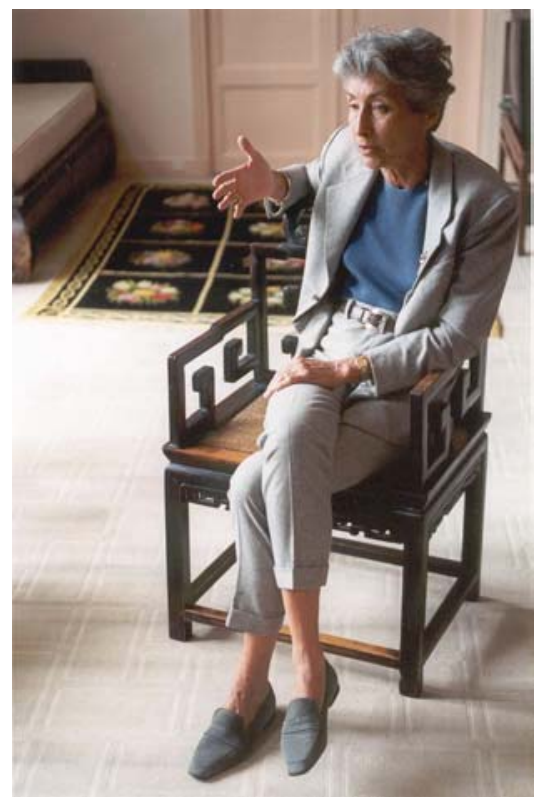

Luiz Eduardo R. Achutti

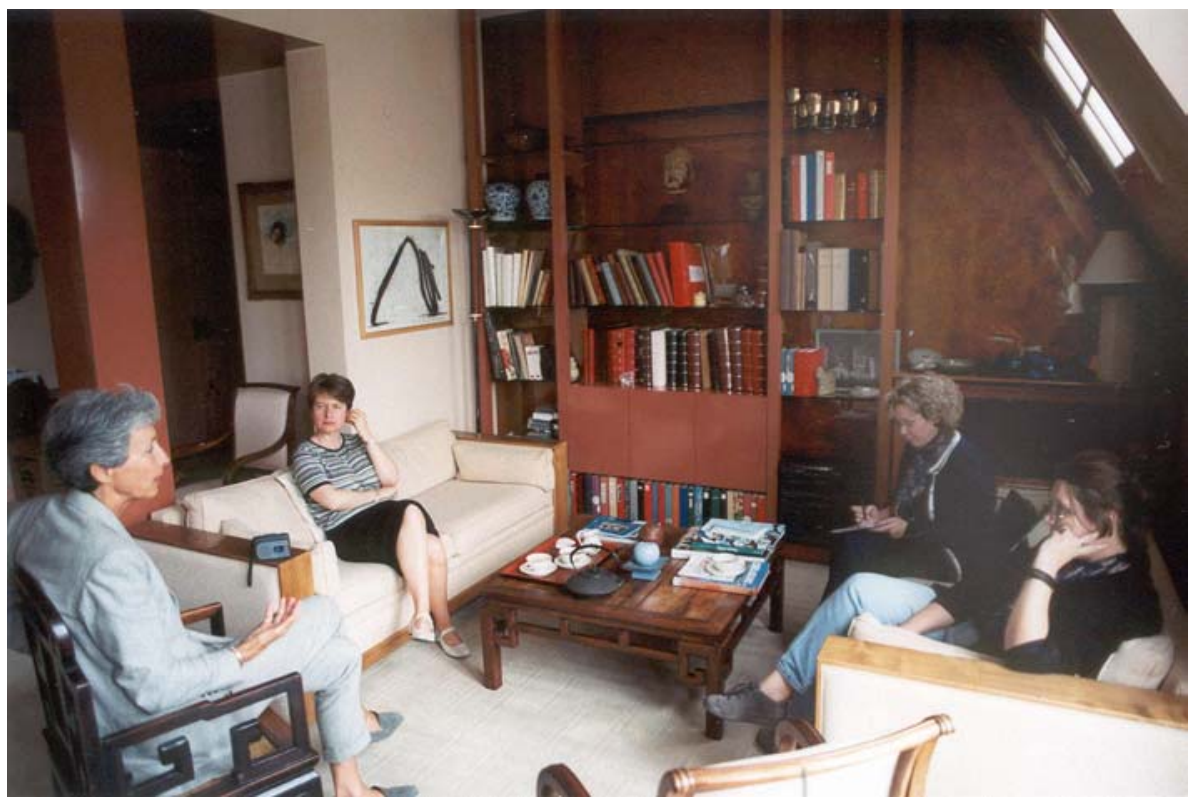

Luiz Eduardo R. Achutti

Horizontes Antropológicos, Porto Alegre, ano 7, n. 16, p. 277-295, dezembro de 2001 
Entrevistadores: Pensamos em iniciar esta entrevista a partir de uma provocação em torno de um tema sobre o qual gostaríamos que a senhora discorresse, em função de sua prática de investigação etnográfica no contexto urbano. Pensamos, por exemplo, no titulo, "Qual é a Antropologia do parentesco e da família no século XXI?" Certamente a sua produção nesta área nos encoraja a iniciar esta entrevista abordando esta questão.

Martine Segalen: E eu gostaria de começar colocando uma contra-questão para vocês: este tema "Antropologia do parentesco e da família" interessa aos pesquisadores brasileiros?

Entrevistadores: Certamente. Este é um dos temas de maior interesse, tanto para pesquisadores seniors, quanto para os mais novos interessados na pesquisa etnográfica sobre a família brasileira e as relações de parentesco presentes, hoje, nas grandes cidades do país.

Martine Segalen: Pergunto isto, porque quando eu revejo o caminho que fiz no meu trabalho e olho a cor dos meus cabelos brancos, pois já faz um bom tempo que trabalho sobre o tema, mas, enfim, quando eu iniciei meu percurso de etnóloga aqui na França, nos anos 60, para se obter uma formação em Etnologia era absolutamente recomendável trabalhar sobre o parentesco. Isto porque, naquele momento, em particular, o pensamento de Claude Lévi-Strauss era predominante na academia antropológica. Quando comecei a trabalhar na área, eu tive a sorte de poder viver uma época em que o interesse pela questão da reprodução e transmissão entre as gerações no meio rural era bastante valorizado. Neste sentido, desde o início de minha formação eu estive engajada nos estudos sobre parentesco e família, tratando da reprodução, da sucessão e da transmissão no contexto das sociedades rurais. Tratava-se de pesquisas nas quais o tema do parentesco/ família despontava como aspecto fundamental. Então, por um lado, estes estudos nos permitiam discutir com os historiadores que trabalhavam sobre questões idênticas às nossas, embora fossem trabalhos mais voltados às sociedades de outras épocas e a partir de pesquisa em arquivos, e, por outro lado, eles permitiam igualmente o diálogo entre os antropólogos que desenvolviam pesquisas sobre o sistema de parentesco nas sociedades atuais e em outras culturas, sob uma perspectiva comparativa. A intenção era, por exemplo, comparar nossos sistemas de parentesco e as novidades nas regras de casamento com aquilo que se passava em outros países. 
Depois disto, eu direcionei minha preocupação, pouco a pouco, para a questão do que é tratar o tema da família e do parentesco no contexto da sociedade contemporânea, e quais são os problemas de metodologia, em particular, que surgem quando se trabalha a nossa própria sociedade.

Ainda hoje, eu comentava com Sophie Chevalier na saída da banca examinadora de uma aluna de Antropologia da qual participamos, que uma espécie de distinção entre os departamentos e disciplinas, faz com que a Sociologia e Antropologia, por vezes, troquem entre si palavras não muito agradáveis e/ou se acusem mutuamente. Estas distinções colocam uma série de limitações no estudo das sociedades contemporâneas. Nessa tese, por exemplo, a examinada recusava-se a utilizar determinadas categorias sociais, sem as quais sua pesquisa etnográfica ficava histórica e socialmente descontextualizada. E justamente, o que caracteriza a sociedade moderna é a presença de categorias sociais. Fala-se, hoje, do predomínio das classes médias, e há, igualmente, referências às pessoas das classes operárias e de classes dominantes que são distingüíveis a partir justamente de categorias sociais. São, pois, conceitos-recursos com os quais devemos dar conta do mundo social.

Mas, no sentido inverso, muitos dos pesquisadores sociais que se interessaram pela Sociologia da Família na década de 1970 e 80, se limitaram a dar conta, sobretudo, do papel do casal. Eles estavam fascinados pelo fato de que o casal se constituía, cada vez mais, a partir de novas formas de união, e que o casamento tornava-se dispensável. Portanto, era o caso, aqui, de localizar a relação entre o casal, o Estado e a política publica, negligenciado nestas pesquisas, e, por conseqüência, a idéia de geração e de transmissão, completamente esquecida. Eu tentei no meu trabalho reconciliar estes aspectos, notadamente, no trabalho que estou publicando agora e que se chama "O espírito de família". Nesse trabalho, que fiz com mais duas colegas, tentamos mostrar que mesmo nas sociedades moderno-contemporâneas, cuja característica é a presença de classes sociais, de um Estado que intervém, e onde a categoria de indivíduo e o "eu" são os valores predominantes, não há impedimentos para que o parentesco, as gerações e a transmissão continuem recursos analíticos fundamentais, mesmo que, sem duvida, trate-se, no caso, da transmissão do patrimônio, etc. 
Entrevistadores: Retomando um pouco um comentário anterior seu, de que modo abordar, então, os problemas metodológicos na pesquisa com família e parentesco nas sociedades urbanas contemporâneas?

Martine Segalen: De fato, efetivamente, se coloca aqui em questão o que era o "bê-a-bá" da Antropologia. Ou seja, o método de observação limitado a um local, digamos, "tradicional". No meu caso, eu apliquei o método da Etnologia clássica, isto é, fui pesquisar em um local singular, numa pequena vila na região da Bretanha. Um lugar que, aliás, não era assim tão pequeno pois de qualquer forma tinha 8.000 habitantes. Eu me inseri no seio de uma família e trabalhei neste meio familiar durante longos anos, mas de uma forma diferenciada dos antropólogos estudiosos de grupos exóticos. Ou seja, eu desenvolvi esta pesquisa durante dez anos, indo várias vezes ao ano para manter o contato com o campo de pesquisa. Foi, portanto, uma longa imersão. Entretanto, trata-se de um ambiente rural, onde esta imersão faz sentido. Já no meio urbano esta atitude não é sensata e/ou é bem mais complexa, uma vez que as pessoas estão espalhadas, as famílias desmembradas, as comunidades locais fragmentadas ou, até mesmo, não existem mais.

Além disso, no que diz respeito ao meio rural, e mesmo às comunidades operárias no contexto urbano até os anos 60 , a questão do parentesco, trabalho, transmissão, sucessão, enfim, tudo isto, tinha uma evidência e exterioridade. Atualmente tudo se mostra de forma mais desarticulada, menos transparente. Assim, é muito mais difícil fazer uma observação participante sobre o parentesco, no meio urbano. Observar o quê? Por onde começar? Certo, alguns rituais particulares se relacionam significativamente ao parentesco mesmo na vida frenética do mundo moderno. Mas nestes contextos (urbanos), a familiaridade do pesquisador deve ser construída pouco a pouco, com questionários e entrevistas flexíveis e deve-se evitar a aproximação com um questionário pré estruturado. Portanto, no que diz respeito a metodologia, certamente a disciplina conheceu várias transformações no estudo do mundo urbano. Inclusive, a problemática é muito mais ampla e interdisciplinar. Por exemplo, a temática do parentesco e da família na sociedade moderna é, atualmente, bastante estudada por juristas. Os juristas cada vez mais desenvolvem trabalhos sobre esta temática, por exemplo, sobre processos de procriação médica e medicamente acompanhada. Os juristas, os filósofos, os sociólogos... Aliás, poderíamos mesmo perguntar: o que os antropólogos têm a dizer sobre o assunto? Portanto, hoje, este não é um tema exclusivo dos 
antropólogos. É preciso nos darmos conta de que a Antropologia está se transformando fundamentalmente, seja nos estudos na sociedade moderna, seja nas ditas "sociedades exóticas". Isto em razão das próprias condições de investigação no campo, hoje, terem também se transformado.

Entrevistadores: Neste sentido de uma preocupação cada vez mais interdisciplinar, pode-se dizer que é fundamental que o antropólogo reflita sobre o papel do Estado, por exemplo, no que diz respeito a um projeto de construção de liberdade individual e emancipação educacional para a cidadania?

Martine Segalen: No que diz respeito à Europa, sim. Ou seja, fala-se na construção de uma Europa que seria, hoje, a Europa social... Agora, quando se analisa a legislação do Estado dos diferentes países, é preciso também considerar as diferenças. Por exemplo, é preciso considerar o fato de que o trabalho das mulheres é enfocado de forma completamente diferente entre as nações. Pode-se observar, por exemplo, que a filosofia alemã é diferente da francesa. Assim, é preciso considerar que na Alemanha, fazendo alusão a uma caricatura, a legislação afirma que a mulher ou trabalha, ou se dedica a ter filhos, enquanto que na França, a política estatal admite que as mulheres-mães trabalhem. Claro que estou forçando, pois estamos falando de escolhas individuais mas, para seguir o exemplo da França, a legislação admite que é do direito da mulher ser mãe e trabalhar ativamente, enquanto, ao contrario, na Alemanha, a mulher deverá escolher, ou ser mãe, ou ser trabalhadora. Portanto, neste sentido, o antropólogo precisaria considerar que há filosofias diferentes em relação à família e parentesco que estão relacionadas à política do Estado, até porque a Antropologia é a disciplina que se apóia na comparação, que se define a partir dela. A Antropologia, é uma disciplina que se convida, ela própria, a sair o tempo todo de um limite nacional para observar e analisar o que acontece em outros lugares e culturas, usando o recurso contrastivo.

Entrevistadores: Justamente, já que se mencionou o método de pesquisa no meio urbano e o fato da disciplina "observar e analisar o que acontece em outros lugares", gostaríamos que a senhora discorresse um pouco sobre sua pesquisa, na França, junto às famílias nanterrianas (de Nanterre), no seu estudo que contrasta a memória de famílias de antigo enraizamento e de recente instalação na localidade. 
Martine Segalen: Sem dúvida, uma via que eu gostaria muito de retomar. Já faz cerca de uns dez anos que não trabalho mais sobre este tema. Após o trabalho que tinha feito sobre o contexto rural, na Bretanha, eu me perguntei, na ocasião, por que não aplicar esta mesma pesquisa em uma cidade? Decidi-me por Nanterre (cidade periférica de Paris), justamente por sua complexidade e processo de modernização. Nanterre, pode-se dizer, é uma anti-cidade, ou seja, ela é a caricatura de uma cidade, pois se compõe de uma quantidade enorme de bairros diversos. Há os bairros velhos e há os novos bairros que foram construídos em torno do monumento "la Défense", que é a uma atração turística em Paris (que, aliás, vocês podem ver da sacada daqui de casa). Nesta pesquisa, eu trabalhei com a rede de parentesco dos habitantes, buscando compreender como eles articulavam a relação entre a história de sua rede de parentesco e a história da cidade. Ao mesmo tempo, esta cidade abrigava um número importante de pessoas idosas e tinha, no passado, a característica de ser receptiva ao viver do idoso. Só que, modernamente, esta população não reconhecia mais os seus espaços numa cidade em constante transformação. $\mathrm{Na}$ ocasião, eu me perguntava qual seria a influência da transformação total de tais espaços nas trajetórias familiares e pessoais da população pesquisada. Mas, de certa forma, eu não considero esta pesquisa finalizada. Essa pesquisa me forneceu um verdadeiro parâmetro que me permitiu relacionar a construção das famílias e a construção da imagem que elas faziam desta cidade. E, paradoxalmente, a mesma problemática que se colocava para os velhos habitantes nanterrianos, pode ser também a questão a ser pesquisada junto às famílias imigrantes, os imigrantes italianos, por exemplo, que conheceram Nanterre, desde sua chegada, por volta dos anos 1930, como uma cidade bem diferente. Na época, Nanterre era ainda a pequena cidade, um vilarejo que crescia ao redor de Paris. Penso, entretanto, que a nova geração de filhos de tais imigrantes não são mais, atualmente, sensíveis a este tema. Por esta razão é que gostaria muito de retomar a pesquisa junto às novas gerações de imigrantes, e analisar como elas articulam suas trajetórias residenciais e trajetórias familiares na cidade.

Entrevistadores: A propósito do tema das redes familiares nas cidades, podemos seguir este percurso e nos perguntarmos como se coloca, hoje, a pesquisa sobre a construção social da identidade? O livro que a senhora 
dirigiu "L'autre et le semblable", foi muito apreciado pelos antropólogos brasileiros com formação intelectual francesa!

Martine Segalen: E imaginem vocês que este livro vai ser traduzido para a língua croata! Eu estou muito orgulhosa disto. Este livro é o resultado de um colóquio, ele próprio resultado de uma comemoração dos cem anos do "Musée National des Arts et Traditions Populaires", na época, local onde eu trabalhava. Foi o momento em que levantamos o debate sobre a identidade, uma vez que o Museu aparece como um lugar onde o tema da identidade se relaciona às coleções organizadas pelos folcloristas, ou seja, uma construção feita pelos folcloristas. Este museu do folclore e das artes populares abrigava tal construção através de coleções sobre as culturas regionais, como a cultura bretã, a basca, etc., e o colóquio acontecia justamente num momento em que o livro de Frederick Barth recolocava em discussão essa noção, ao afirmar que a identidade não era algo pré fixado, uma vez que as fronteiras de sua construção estão sempre em processo de transformação. Este tema das fronteiras simbólicas sempre esteve presente nas minhas pesquisas em Nanterre, embora, mais recentemente, nos meus trabalhos atuais, que se apoiam em entrevistas com quatro gerações de famílias, a problemática da identidade não se coloque mais, da mesma forma que antes, como centro de minhas preocupações e indagações. Bem, este é o movimento da própria Antropologia e das mudanças relacionadas aos acontecimentos. Por exemplo, nesta pesquisa que faço, apoiada em entrevistas com três a quatro gerações, eu inicialmente levantei a questão das possíveis diferenças, bem marcadas entre as famílias originarias da Bretanha e de outra região, mas, depois, tal questão não teve mais sentido, tendo em vista a atual mobilidade social e geográfica, tanto das famílias como dos indivíduos. Não quer dizer que estas famílias não ancorem suas identidades em diversas fases de suas vidas, mas este fenômeno é bem mais flexível. Portanto, o tema da identidade não é mais uma questão central para minha pesquisa atual, e de qualquer forma, acho que houve um excessivo abuso da utilização do conceito de identidade, que me incomoda.

Entrevistadores: E, então, sobre suas produções mais recentes? Pelo que fomos informados a senhora esta trabalhando na publicação desta sua nova pesquisa, não? 
Martine Segalen: Na realidade tenho três livros que vão ser publicados em breve. O primeiro deles, aliás, retoma a questão do método em Antropologia, o que nos remete ao que comentávamos anteriormente. Trata-se de um manual de Etnologia. Na França, em 1975, havia um manual de Etnologia que se intitulava "Elements d'Ethnologie", de Robert Cresswell. Era uma obra que apresentava o "estado de arte" da Antropologia francesa e de suas pesquisas no mundo inteiro, portanto, era um manual que versava sobre a escola de Etnologia francesa na época. Hoje, o livro esta ultrapassado porque a Antropologia mudou e, da mesma forma, o mundo, ou seja, o objeto de estudo da Antropologia, mesmo o objeto clássico. Ainda que Maurice Godelier, em 1963, tenha encontrado, entre os Baruya, um grupo de nativos que nunca havia se confrontado com um homem branco, isto, hoje, não existe mais. Hoje, até mesmo no fundo das florestas, os índios estão se ligando à Internet. Portanto, o mundo e o trabalho de campo se tornaram mais flexíveis à mundialização, às novas comunicações. Enfim, por tudo isto, eu fui estimulada a organizar este novo Manual de Etnologia que faz o "estado de arte" do que é, hoje, a Antropologia na França. Uma Antropologia bem menos voltada a questões teóricas, como há 25 anos atras, quando havia a discussão entre o estruturalismo e o marxismo, duas correntes que debatiam entre si, assim como, no interior do marxismo, havia correntes que se confrontavam, às vezes com discussões bastante violentas, o que não é mais o caso hoje em dia. Não sei se perdemos ou ganhamos! A verdade é que, por um lado, a disciplina antropológica é mais flexível, mais leve, por outro lado, às vezes, tenho a impressão que ela é um pouco algo como um mosaico. Mas, enfim, este é um livro que pude dirigir e que me agrada muito. Gosto muito dos artigos escritos pelos meus colegas e penso que essa obra traz à tona o perfil do que é a disciplina de Antropologia no contexto atual. Um livro onde os estudiosos do exotismo, os "exotizantes", podem fazer uma espécie de reflexão sobre estes movimentos novos, os tais "neos", por exemplo, neo-indigenismo, em que próprios índios, na posição de professores de Antropologia, organizam rituais de tradição para que seus alunos possam observá-los e estudá-los. Enfim, o quadro, hoje, é bem mais complexo.

Há, ainda, um outro livro com base no estudo que realizei com uma colega, sobre uma sociografia dos avós, uma geração um tanto esquecida dos estudos em Ciências Sociais. Nem tanto na Antropologia, pois ela, de 
certa forma, sempre considerou este tema como importante, principalmente nos estudos das sociedades asiáticas ou africanas, onde a relação de avós e netos sempre foi um tema clássico. Entretanto, nas sociedades modernas, além dos psicólogos, poucos têm estudado este grupo social, os avós. Tempos atrás, publiquei um livro sobre o assunto, junto com minha colega Claudine Attias-Donfut, isto é, sobre a importância do papel dos avós na sociedade contemporânea. Este livro obteve muito sucesso. Agora, estamos publicando um segundo livro, na coleção "Autrement", sobre o tema. Uma coleção que, de certa forma, vulgariza, mas no bom sentido, a ciência. Este número é dedicado ao estudo dos avós nas diversas culturas e reúne artigos que tratam do papel destes na Espanha, nos Estados Unidos, na Alemanha, etc. Enfim, um livro que mostra a grande diversidade do papel dos avós nas diferentes culturas.

E finalmente, há o livro Espirito de Família, que escrevi junto com minhas colegas. Um livro cujo objetivo é auxiliar na compreensão das razões pelas quais, nas modernas sociedades contemporâneas, famílias se mantêm ainda unidas, muitas vezes com seus membros mantendo laços bastante fortes entre si mas, ao mesmo tempo, preservando cada um, sua autonomia e independência; é uma tentativa de mostrar, hoje, estas diversas facetas do tema da família, sem receios. Não importa se o livro tende a ser um estudo de Antropologia ou de Sociologia. O que é importante é que buscamos revelar, por exemplo, que a afetividade, hoje, é um fenômeno bastante valorizado entre as gerações. Este tempo para o afeto, no caso da França, funciona graças à eficácia do Estado providência. Eu explico: a aposentadoria é assegurada às pessoas na França, o que faz com que, depois de 25 anos de trabalho, os aposentados sejam autônomos, e tenham sua independência financeira. Não dependem mais de seus filhos na velhice. Os pais, com a aposentadoria garantida, não esperam nada dos filhos, o que faz com que os laços entre as gerações se tornem, paradoxalmente, fortes, sem tratar-se de laços de dependência econômica. Se em outras sociedades, de modo geral, os velhos eram, ou são, dependentes de seus filhos, na França, este não é o caso. Esta autonomia, ou independência dos velhos permite o desenvolvimento de laços familiares baseados no afeto, ao contrário do que supunham cientistas sociais no passado, sobre as relações familiares na França moderna. Talvez, inclusive, laços mais puros, se pensarmos na linha da tese desenvolvida por Anthony Guiddens, teórico da modernidade. 
Eu espero que este livro venha a ser compreendido pelos antropólogos, pois é minha maneira de estudar a modernidade. Sempre é dito na academia antropológica que é bom estudar o parentesco, mas o desafio é estudar o parentesco onde ele é algo, por vezes, invisível porque as pessoas não moram mais necessariamente juntas e a co-habitação, às vezes, envolve uma série de questões a serem analisadas. Mas, mesmo no caso de membros de uma família estarem distanciados, as relações afetivas precisam ser consideradas no âmbito dos novos meios de comunicação e novas tecnologias. As famílias estão bem mais aproximadas no ano 2000 do que estavam nos anos 1930.

Entrevistadores: Gostaríamos de lhe confiar uma sensação com a qual não sabemos se a senhora concorda: mesmo levando em conta seus trabalhos, que consideramos de Antropologia urbana e as pesquisas desenvolvidas pelos laboratórios de Antropologia Urbana, no CNRS por exemplo, pode-se dizer que na França os estudos antropológicos continuam predominantemente voltados para as sociedades africanas e/ou outras ainda ditas tradicionais!

Martine Segalen: Sei que vocês conhecem bem vários antropólogos franceses que estudaram o fenômeno urbano, como Colette Pétonnet e Jacques Gutwirth, que sempre falaram com muito carinho de Porto Alegre, onde tiveram a oportunidade de desenvolver cursos. Sem duvida, é um grupo pouco numeroso que nutre esta preocupação com relação à Antropologia urbana. No meu caso, pode-se dizer que sou um pouco isolada na minha área de estudos. Eu, por exemplo, não criei uma escola. Agora devo acrescentar que não criei um centro de pesquisa, devido à minha própria trajetória pessoal, pois eu era diretora de um grande centro de pesquisa, Centro de Etnologia Francesa, associado ao museu de artes e tradições populares. Instituição de cunho generalista que dirigi durante dez anos.. Quando me afastei deste centro foi que retornei à Universidade, estando inserida, hoje, em um grande departamento. Acho, hoje, que, se eu trabalhasse mais uns vinte anos, teria condições de fato de vir a criar um centro de pesquisa, uma vez que estou relacionada com o ensino no mestrado e doutorado, mas... (ri e faz alusão aos seus cabelos brancos). Em todo caso eu oriento temas diversos e também sou aberta a uma diversidade de temas. Este não é um mérito meu, isolado. Em meus trabalhos eu sempre segui a orientação de 
meu mestre que foi Alain Girard, que era demógrafo no INED (Instituto Nacional de Demografia). Foi ele quem lançou a primeira pedra e eu o segui. E, como muitas coisas me interessavam, isto fez com que meu trabalho esteja inscrito entre diversas tradições de disciplinas (Antropologia, Sociologia, Demografia, Geografia, História). Veja, por exemplo, o trabalho que produzi sobre o parentesco e o sistema de reprodução no meio camponês. Trata-se de um trabalho que sofre a influencia da reflexão nos anos 1970-80, logo, eu fui igualmente motivada por uma dinâmica de trabalho de grupo interdisciplinar. Com relação ao trabalho que venho fazendo, os sociólogos, por um lado podem argumentar que não é suficientemente quantitativo, por outro, os antropólogos podem dizer que exagero em tratar da política pública e social. De qualquer forma, o parentesco, de modo geral, nunca foi um tema da moda em nossas sociedades. O tema família, sim, foi e é um tema que produz uma preocupação social.

Mas só para retomar a questão, sem duvida, existe o trabalho bem sucedido do Laboratório de Antropologia Urbana, trabalhos como os de Colette Pétonnet, Jacques Gutwirth, Patrick Williams e Jean-Pierre Hassoun. Há o trabalho de Sophie Chevalier, aqui presente, de que gosto muito e que trata dos objetos e decoração no mundo doméstico, entre outros.

Entrevistadores: Aliás, Sophie publicou no número 13 de Horizontes Antropológicos, dedicado à temática da Cidade Moderna, o artigo "Intérieurs domestiques urbains en France et en Angleterre". Foi uma ótima contribuição. Mas a partir deste panorama que a senhora nos traçou sobre o seu trabalho e o do Laboratório de Antropologia Urbana do CNRS, lhe perguntamos se, hoje, poderíamos falar de uma Antropologia francesa, ou de uma Etnologia francesa, tal qual se diria trinta ou quarenta anos atrás?

Martine Segalen: Naquela época, eu diria que o que caracterizava a Antropologia científica na França era o estudo da sociedade rural francesa. Essa época corresponde à minha iniciação na Etnologia. Desde então, o Centro de Etnologia Francesa acolheu um numero enorme de pesquisadores com estudos inovadores. No período em que dirigi o museu, por exemplo, existia uma crise enorme entre a política do próprio museu e a política de pesquisa no seu interior. Acho que, agora, efetivamente toda a pesquisa deve ser comparativa. Trata-se de trabalhar "em relação", ou seja, de se manter o olhar comparativo. Em meus estudos, por exemplo, eu busco sempre estar 
atenta à política pública sobre a família na Europa pois ela é necessária para minha pesquisa. Mais tarde, certamente, deverá haver uma mudança no encaminhamento de uma política de pesquisa no Centro de Etnologia Francesa. Na medida em que ele se mantiver associado ao Museu, haverá a necessidade de se produzir uma Antropologia da Europa, ou pelo menos, do sul da Europa. Em todo o caso, para mim, que acredito que o "bê-a-bá" da Antropologia se apóia sobre a pesquisa etnográfica, é importante que tais estudos não sejam extensivos, pois é importante que a pesquisa se ancore, de alguma forma, numa localidade.

Entrevistadores: E o que poderíamos dizer sobre os rituais do e no mundo contemporâneo? Por exemplo, sabemos ser a prática da maratona um tema de pesquisa que lhe é bastante caro.

Martine Segalen: Bem, eu fiz esta pesquisa porque eu mesma sou maratonista. Portanto, primeiro era a minha prática privada. Depois, vocês sabem, um antropólogo precisa se familiarizar com aspectos que lhe são estranhos e, neste caso, eu tentei estranhar algo que me era muito familiar. Depois de vinte e cinco anos de prática maratonista, me dei conta de que esta prática havia sofrido imensas transformações, a ponto de reunir milhares de pessoas, enquanto que no passado reunia umas dez pessoas. Imaginem vocês que, em Barcelona, uma maratona reúne algo em torno de 80.000 pessoas. É algo impressionante. Por isto, ponderei que havia aí uma verdadeira questão etnográfica, uma questão sociológica. Algo que a Antropologia urbana poderia questionar! As pessoas maratonistas dizem que buscam a natureza, o ar puro, a floresta, etc. Mas, finalmente, todos se concentram numa grande cidade, e não há nenhuma grande cidade do mundo que não tenha tido uma grande maratona. Inclusive, as cidades asiáticas, logo que deixaram de ser comunistas, para emblematizar o significado da liberdade dos novos tempos, fizeram o quê?... criaram uma maratona. Sim, eu analisei a maratona enquanto um rito contemporâneo, mas num sentido amplo. Além disto, eu retomei depois o tema dos rituais de casamento. Eu já havia trabalhado com o tema dos casamentos no meio rural. Um tempo depois, um colega do Quebec me colocou a seguinte questão: por que os franceses que vivem no Canadá desenvolvem muito menos rituais que os franceses que moram na França? Aliás, segundo ele, não se encontrariam os mesmos ritos entre as pessoas de origem francesa, residentes no Quebec, comparativamente 
aos que vivem na França. Eu fui, então, pesquisar em Poitu, porque haviam vários quebequienses de origem Poitu e investiguei o fato do casamento não se colocar mais para as pessoas que optavam pela coabitação, como um rito de passagem. Tratei, aqui, da questão da identidade articulando-a à questão da transformação da família no mundo contemporâneo.

Entrevistadores: Achamos que numa revista onde o tema da natureza e cultura está tradicionalmente vinculada ao desenvolvimento de museus antropológicos, poderíamos desviar um pouco para o tema dos museus. Como a senhora foi, por mais de dez anos, responsável pelo Centro de Etnologia Francesa, vinculado ao Museu Nacional de Artes e Tradições Populares aqui em Paris, gostaríamos de saber a sua opinião sobre a crise que envolve a política de museus etnológicos da França e que ira provocar o desaparecimento deste museu, assim como o "Musée de l'Homme".

Martine Segalen: Sim, esta é, de fato, uma historia muito complicada. A crise existe em todos os museus. Por exemplo, o Museu de Artes e Tradições Populares obteve bastante sucesso até os anos 1980. Depois, iniciaramse alguns problemas de proposta. Por exemplo, a este museu se ligava uma coleção de etnologia rural, com um laboratório de pesquisa que se dedicava a todos os domínios da Etnologia. Depois disto, na França, nos anos 80, tivemos um movimento de patrimonializacão no âmbito do qual um número muito grande de museus locais se desenvolveram, por exemplo, os museus de identidade local e regional. Estes museus obtiveram muito mais sucesso que o nosso, nacional e, ao longo deste processo, acusaram os museus como o nosso de Artes e Tradições Populares, de não ter se renovado na forma de apresentação das coleções e acervo, enquanto que os museus regionais funcionavam muito bem. Bom, ao mesmo tempo, o Museu do Homem estava em crise. O que posso dizer é que vai haver um novo Museu do Homem que, aliás, não tem um título até o momento, e que este novo museu é fonte de debate para os etnólogos que temem que seja um museu de arte, e não um museu de etnologia.

Em um determinado momento pensamos que haveria uma re-fusão entre nosso Museu de Folclore e de Artes Populares e o Museu do Homem, pois o primeiro pertencia a este último até 1937, o que poderia ter sido um grande museu das civilizações, onde a Europa poderia ser tratada da mesma forma que outras áreas culturais. Resultado: todo o esquema de renovação 
fracassou e o Ministério da Cultura resolveu subvencionar o novo museu, até porque este é o projeto do atual Presidente da República, Sr. Jacques Chirac, que busca construir seu monumento, assim como François Miterrand que, com seus projetos, construiu a nova Biblioteca Nacional, a pirâmide do Museu do Louvre, etc. Enfim, o novo museu será construído na cidade de Marseille no sul da França (resultado da ação do senhor Michel Colardelle) e toda a coleção de arte popular, arte africana e da oceania, vai ser transferida para lá. Assim, em 2008, em Marseille, uma belíssima construção do século XVII, o antigo forte Saint Jean, e mais outro edifício ao lado deverão abrigar as coleções do antigo Museu de Artes e Tradições Populares. Será, assim, o museu da Europa e dos países mediterrâneos, com exposições temporárias e não um museu de coleções permanentes. E com isto, um museu que reúne questões tratadas tanto por etnologias quanto por sociólogos, geógrafos, etc.

De qualquer maneira, Marseille é uma grande cidade e este projeto recebeu lá financiamento que jamais encontraria aqui em Paris. Além disto, soma-se o fato de que, na política de museus, na França, sempre predominou uma lógica de Museu de Belas Artes. Jamais se compreendeu o que era um museu etnológico, jamais. Aliás, isto me decepcionou e fez com que eu deixasse uma instituição onde eu passei toda minha vida.

Entrevistadores: Certamente, seu afastamento do Centro de Etnologia Francesa não lhe impediu de continuar o desenvolvimento de novos projetos. Gostaríamos de saber se em seus planos mais recentes inclui-se alguma ida ao Brasil, ou a Porto Alegre?

Martine Segalen: Eu gostaria muito de ir a Porto Alegre. Já fui ao Rio de Janeiro e, inclusive, tenho que retornar. Tenho um projeto com o antropólogo Kant de Lima, da Universidade Federal Fluminense. Atualmente temos um intercâmbio em torno de uma pesquisa que trata dos "guardiões de imóveis", ou seja, os porteiros de edifícios que sempre ocuparam um papel muito importante na sociedade parisiense. O porteiro é um personagem emblemático de Paris e foi criado pela reforma de Haussman, pois a arquitetura dos imóveis deveria obedecer a um conceito de vigilância, sendo que tais edifícios deveriam ser guardados e vigiados para evitar a entrada de estrangeiros, etc. Os porteiros eram denominados, antigamente, de "cordon, s'il vous plait" (o que poderia ser traduzido como "puxa saco"). Alguém 
servil, que deveria vigiar e se manter no limite entre o espaço privado e o publico. Bem, a pesquisa gira em torno do papel que cumpre, hoje, este personagem, já que, com o passar do tempo, eles se profissionalizaram. É interessante estudar-se a trajetória profissional ou pessoal destes porteiros, por exemplo, como chegaram a ser porteiros. Aqui na França, o porteiro é o guardião e vigilante, e ele sabe tudo.

Entrevistadores: Estes personagens urbanos devem ter tido um papel estratégico no período da guerra, em que a cidade de Paris estava ocupada pelos alemães, não?

Martine Segalen: Certamente. Como exemplo posso citar o caso de minha família que é judia. Minha mãe teve a experiência de ter sido denunciada pela guardiã do seu edifício no período da II Grande Guerra. Meu pai já havia sido embarcado. Eu era ainda criança e estava com minha mãe. Estávamos escondidas na casa da minha avó. Quando a polícia francesa chegou para recolher os judeus, perguntaram pela minha mãe. A guardiã poderia ter dito que não sabia onde estávamos mas ela deu o endereço de minha avó, nos delatando. Obviamente, nem todos era assim, mas infelizmente eu só posso dizer um doloroso "obrigado, senhora, hem"!

Muitos dos porteiros que conhecemos, hoje, vieram para Paris nos anos 1960, e eles ocuparam, no mercado de trabalho, o lugar deixado pelos franceses que estavam ascendendo profissionalmente e, na ocasião, não queriam mais fazer este tipo de trabalho. Considerando ainda que o espaço onde residiam era muito pequeno e desconfortável, não tinha banheiro, além do salário ser menor, esta tarefa tornava-se cada vez mais socialmente desvalorizada. Os imigrantes portugueses aceitavam estas condições de emprego, e vieram em massa. Mas, hoje, as condições de moradia e de remuneração melhoraram. Houve épocas, inclusive, em que a maioria dos porteiros era imigrante e a inserção nesta profissão, basicamente, funcionava graças às redes de parentesco entre os imigrantes já instalados na cidade e os recém chegados. Da mesma forma, há toda a questão relacionada com a arquitetura parisiense, pois antigamente havia o quarto dos serviçais, que era algo horrível. Hoje, estes portugueses moram em melhores condições e ainda puderam fazer economias e construir enormes casas no seu país natal, para sua aposentadoria. Assim, mesmo que vivam o cotidiano em Paris em pequenos apartamentos, em Portugal possuem belas casas. Nos anos 1980, 
com a crise de empregos e aposentadoria, pode-se dizer que há, novamente, o retorno de um grande numero de porteiros franceses, geralmente pessoas que vem do norte, desempregados.

Discutindo este tema com os colegas brasileiros, nós chegamos à conclusão de que poderíamos fazer um estudo comparativo com os porteiros do Brasil. Este é um projeto de pesquisa comparativa franco-brasileira. Todas estas observações me colocam face ao tema das fronteiras entre o espaço privado e espaço público, espaço vigiado ou não, no caso das sociedades contemporâneas.

Entrevistadores: Bem, dado o avançado da hora, só nos resta lhe agradecer esta oportunidade, esperando poder, em breve, lhe receber no Programa de Pós-Graduação em Antropologia Social (UFRGS), em Porto Alegre.

Martine Segalen: Foi um prazer. E basta me convidar, que irei a Porto Alegre. Então, até breve.

\section{Bibliografia sugerida da autora}

SEGALEN, Martine. Les confréries dans la France contemporaine: les Charités. Paris: Flammarion, 1975.

. Confrérie des pénitents blancs (Le Puy). La Confrérie des pénitents blancs du Puy. Paris: G. P. Maisonneuve et Larose, 1978.

. Mari et femme dans la société paysanne. Paris: Flammarion, 1980.

- Quinze générations de bas-bretons: parenté et société dans le pays bigouden Sud, 1720-1980. Paris: Presses Universitaires de France, 1985.

. Sociologie de la famille. Paris: Éd. de la Maison des Sciences de l'Homme, 1986.

. Objets domestiques de la vie ouvrière. Transmissions et ruptures dans les familles de Nanterre. Ethnologie Française, Paris, XVII, 1, p. 29-38, 1987.

. (Dir). L'Autre et le semblable: regards sur l'ethnologie des sociétés contemporaines. Paris: Presses du CNRS, 1989.

Nanterriens, les familles dans la ville: une ethnologie de l'identité.

Toulouse: Presses Universitaires du Mirail, 1990.

Jeux de familles. Paris: Presses du CNRS, 1991.

. Rites et rituels contemporains. Paris: Nathan, 1998.

Horizontes Antropológicos, Porto Alegre, ano 7, n. 16, p. 277-295, dezembro de 2001 
SEGALEN, Martine. Sociologie de la famille. (5 $5^{\text {ème }}$ éd.). Paris: Armand Colin, 2000. . Ethnologie: concepts et aires culturelles. Paris: Armand Colin, 2001.

SEGALEN, M.; ATTIAS-DONFUT, C. Grands-parents: la famille à travers les générations. Paris: O. Jacob, 1998.

SEGALEN, M.; BROMBERGER, C. L'objet moderne: de la production sérielle à la diversité des usages. Ethnologie Française, Paris, v. 26, n. 1, p. 5-16, 1996.

SEGALEN, M.; BURGUIÈRE, A.; KLAPISCH-ZUBER, C.; ZONABEND, F. (Dir.). Histoire de la famille. Paris: Armand Colin, 1986. 2 v.

SEGALEN, M.;CHAMARAT, J. Amours et mariages de l'ancienne France. Paris: Berger-Levrault, 1981.

SEGALEN, M.; CUISENIER, Jean. Ethnologie de la France. Paris: Presses Universitaires de France, 1986. (Collection Que sais-je?).

SEGALEN, M.; FRÈRE-MICHELAT, C. Les enfants d'Achille et de Nike: une ethnologie de la course à pied ordinaire. Paris: Ed. Métailié, 1994.

SEGALEN, M.; LE WITA, B. Se battre comme des chiffonniers. Etudes Rurales, Paris, 4, 95-96, p. 205-211, 1984.

SEGALEN, M.; LE WITA, B. (Dir). Chez-soi. Objets et décors: des créations familiales?, Autrement, Paris, 1993.

SEGAlEN, M.; MICHELAT, C.; COADOU, M.-A. Anthropologie sociale et ethnologie de la France: actes du colloque du Centre d'Ethnologie Francaise et du Musée National des Arts et Traditions Populaires. Louvain-la-Neuve: Peeters, 1989.

SEGALEN, M.; RAVIS-GIORDANI, G. Les cadets [colloque, 1991, Chartreuse de Pontignano, Italie] / [organisé par le Laboratoire d'ethnologie méditerranéenne et comparative (URA-CNRS); Cambridge Group for the History of Population and Social Structure; Laboratorio Etno-Antropologico de 1'Université de Sienne] Paris: CNRS, 1994. 